\title{
Science and mathematics teacher communities of practice: social influences on discipline-based identity and self- efficacy beliefs
}

Samuel J. Polizzi ${ }^{1}$, Yicong Zhu' ${ }^{2}$, Joshua W. Reid', Brandon Ofem³ ${ }^{3}$ Sara Salisbury ${ }^{4}$, Michael Beeth ${ }^{5}$, Gillian Roehrig ${ }^{6}$, Margaret Mohr-Schroeder ${ }^{7}$, Keith Sheppard ${ }^{8}$ and Gregory T. Rushton ${ }^{1,9^{*}}$ (D)

\begin{abstract}
Background: Teacher communities of practice, identity, and self-efficacy have been proposed to influence positive teacher outcomes in retention, suggesting all three may be related constructs. Qualitative studies of communities of practice can be difficult to empirically link to identity and self-efficacy in larger samples. In this study, we operationalized teacher communities of practice as specific networks related to teaching content and/or pedagogy. This scalable approach allowed us to quantitatively describe communities of practice and explore statistical relationships with other teacher characteristics. We asked whether these community of practice networks were related to identity and self-efficacy, similar to other conceptualizations of communities of practice.

Results: We analyzed survey data from 165 in-service K-12 teachers prepared in science or mathematics at 5 university sites across the USA. Descriptive statistics and exploratory factor analyses indicated that math teachers consistently reported smaller communities of practice and lower identity and self-efficacy scores. Correlations revealed that communities of practice are more strongly and positively related to identity than self-efficacy.

Conclusion: We demonstrate that teacher communities of practice can be described as networks. These community of practice networks are correlated with teacher identity and self-efficacy, similar to published qualitative descriptions of communities of practice. Community of practice networks are therefore a useful research tool for evaluating teacher characteristics such as discipline, identity, self-efficacy, and other possible outcomes (e.g., retention). These findings suggest that teacher educators aiming to foster strong teacher identities could develop pre-service experiences within an explicit, energizing community of practice.
\end{abstract}

Keywords: Social network analysis, Science teacher education, Mathematics teacher education, Identity, Selfefficacy, Communities of practice, Visual network scales

\footnotetext{
* Correspondence: gregory.rushton@mtsu.edu

${ }^{1}$ Tennessee STEM Education Center, Middle Tennessee State University,

Murfreesboro, TN 37132, USA

${ }^{9}$ Chemistry Department, Middle Tennessee State University, Murfreesboro, TN

37132, USA

Full list of author information is available at the end of the article
}

\section{Springer Open}

(c) The Author(s). 2021 Open Access This article is licensed under a Creative Commons Attribution 4.0 International License, which permits use, sharing, adaptation, distribution and reproduction in any medium or format, as long as you give appropriate credit to the original author(s) and the source, provide a link to the Creative Commons licence, and indicate if changes were made. The images or other third party material in this article are included in the article's Creative Commons licence, unless indicated otherwise in a credit line to the material. If material is not included in the article's Creative Commons licence and your intended use is not permitted by statutory regulation or exceeds the permitted use, you will need to obtain permission directly from the copyright holder. To view a copy of this licence, visit http://creativecommons.org/licenses/by/4.0/. 


\section{Introduction}

The recruitment, training, and retention of $\mathrm{K}-12$ teachers is of intense interest as countries prepare for an increasingly global economy and society (Darling-Hammond, 2017). Retention efforts are particularly important for early career teachers, with as high as $50 \%$ of teachers reported to leave within the first 5 years of teaching (Ingersoll \& Smith, 2003). Retention scholars have argued for shifts beyond a short-term focus on teacher content preparation to more holistic approaches of retention through the development of teacher professional communities, identities, and selfefficacy (Darling-Hammond et al., 2017). Teacher development and induction programs can provide various community supports for teachers, such as social interactions with novices, mentors, and administrators (Ingersoll, 2012), and these supports are generally accepted to have positive effects on career outcomes in retention, classroom practices, and student achievement (i.e., effectiveness) (Ingersoll \& Strong, 2011). However, in the USA, national reform documents question how teacher support programs are evaluated, stating that "there is little firm empirical evidence to support conclusions about the effectiveness of specific approaches" (pg. 4) (National Research Council, 2010). Despite a decade of public and private funding of programs emphasizing quality teacher preparation and training (Reckhow \& Snyder, 2014; Richardson, 2018), the field continues to suffer from a lack of empirical data about teacher variables (e.g., identity, self-efficacy, and communities of practice) across multiple programs, particularly in regard to how these constructs are related to science, technology, engineering, and mathematics (STEM) teacher development. Additional systematic studies are needed in these STEM contexts to understand the relationships between constructs, which contribute to broader teacher outcomes (e.g., classroom effectiveness and retention in the profession) in national teacher development models.

Teacher identity and self-efficacy have been linked to teacher retention in the profession (Hong, 2010; Sutherland, Howard, \& Markauskaite, 2010; TschannenMoran, Hoy, \& Hoy, 1998). Teacher identity has been referred to as a complex, dynamic self-image related to the multiple roles a teacher assumes (Beijaard, Meijer, \& Verloop, 2004). Therefore, it is tightly connected to the context and activities surrounding a teacher at any given time. Studies support that teacher identity influences teacher performance (Eick \& Reed, 2002; Helms, 1998; Luehmann, 2008) and can mediate a desire to leave poor working conditions (Moore \& Hofman, 1988).

Related to identity is self-efficacy or beliefs in one's own competencies to carry out a given activity (Bandura, 1977). Teachers with higher self-efficacy are more likely to exhibit effective teaching behaviors that improve student motivation and academic achievement (Caprara, Barbaranelli, Steca, \& Malone, 2006; Tschannen-Moran
\& Hoy, 2001) and report higher levels of commitment to the profession (Chan, Lau, Nie, Lim, \& Hogan, 2008; Rots, Aelterman, Vlerick, \& Vermeulen, 2007). Lower self-efficacy negatively impacts job satisfaction, decreases the ability to manage stress (Klassen \& Chiu, 2010), and may lower the likelihood of persisting in the profession (Ingersoll, 2001). Ware and Kitsantas (2007) discussed this relationship as self-efficacy beliefs shielding teachers from lowered commitment and increased attrition, suggesting self-efficacy is a target for professional development with the goal of improving retention.

Social interactions are key components of the identity, self-efficacy, and retention constructs described above. Interactions within communities of practice (CoP; i.e., groups of people who interact to improve a shared craft; Wenger, 1998) have previously been examined as a means to understand teacher identity and how it develops (Friedrichsen, Lannin, Abell, Arbaugh, \& Volkmann, 2008; Luehmann, 2007; Varelas, House, \& Wenzel, 2005). Ofem et al. (2021) have studied teacher interactions using social network analysis (SNA) to correlate network structures and self-efficacy, reporting that male teachers experienced higher self-efficacy when perceiving they were part of more dense networks. Soltis, Agneessens, Sasovova, and Labianca (2013) also used SNA to describe interactions within a professional community, and found it was not only the number of connections in that community, but also the direction and obligatory nature of those interactions, that predicted job turnover intentions within a life science company. These separate studies support empirical links between identity, self-efficacy, and social interactions. Further, they highlight the potential for additional research to quantify and link teacher communities to desirable individual traits and workforce stability.

\section{Literature review}

Teaching is inherently a social endeavor, and an increasing proportion of beginning teachers are reported to receive structured social interactions, or induction support, designed to help transition them into teaching and school culture (Ingersoll, 2012). Chief among induction supports were supportive communication with an administrator, ongoing guidance and feedback from a mentor, group seminars, and common collaboration time within their subject-discipline. Ultimately, the interactions provided by induction programs have been linked with positive outcomes in teacher retention, classroom practices, and student achievement (Ingersoll \& Strong, 2011). We situate this manuscript within sociocultural learning theory which posits that participation within cultural settings can influence the development of an individual (Vygotsky, 1980). For teachers, these 
cultural settings include social interactions through CoP, which have previously been linked to teacher identity and self-efficacy development (McIntyre \& Hobson, 2015; Skaalvik \& Skaalvik, 2011). Below, we provide a literature synthesis of teacher CoP, social networks, teacher identity, and self-efficacy.

\section{Communities of practice}

Scholarship on what it means to learn has been approached from two metaphorical perspectives: acquisition and participation (Sfard, 1998). An acquisition metaphor of learning highlights the individual as a consumer of knowledge whereas the participatory metaphor suggests learning to occur through active participation within a community of practice (Sfard, 1998). Lave and Wenger (1991) discuss learning from a participatory stance when they describe learning as situated within social contexts. Within these social contexts, individuals interact with one another as well as with cultural objects (i.e., policy initiatives; Lave \& Wenger, 1991; Korthagen, 2010). Through these interactions, novices participate at a periphery to the more expert others through apprenticeships and work their way to becoming a full and legitimate participant of the community (i.e., legitimate peripheral participation; Lave \& Wenger, 1991). Wenger (1998) referred to these communities as communities of practice. A CoP refers to the myriad landscape of relationships between people and culture within an environment (Wenger, 1998). Within educational systems, novice teachers learn the practices and tacit knowledge of the trade (i.e., teaching) through their actions and social interactions with expert practitioners (i.e., veteran teachers).

\section{A community of practice is a specific type of social network}

Teacher CoP has been largely studied in respect to the more abstract characteristics they foster (i.e., identity, self-efficacy), but less so in regard to the interactional nature of the CoP. Teacher $\mathrm{CoP}$ has been described as a group of educational stakeholders who interact around domains of knowledge (i.e., pedagogical, disciplinary) and practices. This recognizes the relational status of a $\mathrm{CoP}$, in which teachers interact with others to inform their practice, and the cultural component of a CoP, in which teaching is the common interest that connects them. This is consistent with Wenger's (1998) influential work on CoP, in which community members serve as a broader, living curriculum for the training of apprentices, which may be more valuable for the evolving demands of a practice than past instruction about a practice.

Research provides some evidence that teacher CoP can foster social spaces for identity development, self-efficacy growth, and therefore, retention in the profession (Goos \& Bennison, 2008; Kelley, Knowles, Holland, \& Han, 2020; Simpson \& Bouhafa, 2020). For instance, research suggests that a supportive, collaborative work environment with cohesion among education stakeholders lowers the likelihood of teacher attrition (Billingsley, 2004; Buchanan, 2012; Hausman \& Goldring, 2001; Mack, Johnson, JonesRincon, Tsatenawa, \& Howard, 2019). In a recent study, Kelley et al. (2020) found that teachers who participated in a STEM community of practice increased their selfefficacy related to teaching. Regarding identity, Luehmann (2007) discussed CoP as a "safe space" (p. 828) where teachers discover, construct, and try new identities. For example, a novice teacher may be leaving the pre-service/ student identity behind and forming an in-service/teacher identity when entering a teacher community of practice. Another example is through interactions within the safety of a CoP, where a teacher may realize they are not a fully didactic or Socratic instructor like other members of the $\mathrm{CoP}$, but instead they have an identity in between. Within these social spaces, teachers assess their roles and alignment (or misalignment) with the broader school community. However, these studies are limited in their capacity to propose mechanisms for why CoP is related to these constructs. Considering the structural characteristics of CoP within a network theory framework (e.g., Schenkel, Teigland, \& Borgatti, 2001) could provide insight into these mechanisms.

\section{Teacher identity}

The teacher identity literature reveals a consistent acceptance of different identities and/or sub-identities for teachers (Alsup, 2006; Beauchamp \& Thomas, 2009; Sutherland et al., 2010). In their review of scholarship on teacher identity, Beijaard et al. (2004) found that teacher identity varies widely in how it is operationalized across studies. However, common themes were found, including that identity is treated as complex and dynamic (Beijaard et al., 2004). Teacher identity is complex in that teachers may hold multiple components to their identity including, but not limited to, that of a discipline-based teacher (e.g., science or mathematics teacher), curriculum developer, teacher-leader, and after-school tutor (Beauchamp \& Thomas, 2009; Beijaard et al., 2004; Eick \& Reed, 2002). In this study, we operationalize teacher identity from a discipline-based perspective, whereby identity is a socially constructed self-image as a teacher of either mathematics or science.

Chi (2009) investigated a conceptual model of Science Teacher Identity (STI) that included personal experience, knowledge and skills, community practice, science teaching practice, degree of success, social respect, beliefs and values, intrinsic satisfaction, and representation (Supplemental Table S1). A 48-item STI questionnaire 
was developed from Helms' (1998) model of identity, Danielewicz's (2001) principles of pedagogy, and Starr et al.'s (2006) survey of teacher identity in clinical physician educators. Longitudinal use of the overall STI instrument allowed teachers to be divided into three levels of science teacher identity (i.e., strong, moderate, weak) and indicated that some participants had significant gains in their identity after a teacher preparation program, rising from weak to moderate or moderate to strong (Chi, 2009). Use of the "community practice" component distinguished between experience levels, with pre-service teachers displaying significantly lower scores than experienced teachers. This temporal distinction can be interpreted as fewer opportunities for participation in a teacher CoP relating to lower teacher identity. The finding also illustrates the potential usefulness of the STI instrument.

Sammons et al. (2007) also described a multi-component structure of identity that may affect teacher instructional and retention outcomes differently if situational, professional, and personal identities are in conflict or alignment. Hong (2010) found that early career teachers experienced emotional burnout when their professional identities were not supported by their environment (e.g., Socratic teaching style conflicts with standardized testing responsibilities), which then led to attrition. This framing is consistent with Sutherland et al.'s (2010) proposal that developing the professional identity of a teacher is an important target for early career teachers, since this period can be marked by intense conflict or alignment with professional demands. One contextual factor to consider for targeted professional development are the social interactions that shape identity development processes. Social networks provide the social spaces where significant interactions can occur to mitigate identity conflicts and ultimately shape identity (Luehmann, 2007; Luehmann \& Tinelli, 2008; McIntyre \& Hobson, 2015; Sweitzer, 2009). In the present study, we aim to further examine the utility of discipline-based identity for understanding science and math teacher development, particularly as it relates to CoP networks and self-efficacy.

\section{Teacher self-efficacy}

The concept of self-efficacy has been well explored over the past four decades. Two primary traditions are at the root of self-efficacy conceptualizations. Self-efficacy research is traditionally either based in either Rotter's (1966) social learning and locus of control theories or Bandura's (1977) social cognitive theory. While Rotter's social learning theory posits that an individual's confidence is an extension of their beliefs about what they can control in their environment, Bandura's social cognitive theory posits that self-efficacy arises from a person's beliefs about their own competence (Tschannen-Moran et al., 1998). Using components of Bandura's conceptualizations of self- efficacy, Gibson and Dembo (1984) developed the teacher efficacy scale (TES) instrument to measure self-efficacy. Gibson and Dembo (1984) completed a factor analysis of the TES model and extracted two factors: personal teaching efficacy and general teaching efficacy. Later, Friedman and Kass (2002) presented a conceptualization of self-efficacy that embraced two major domains of a teacher's function: working with students in the classroom and participating as a member of the school organization or community. In this study, we base our conceptualization in Bandura's body of work. Bandura (1977) describes self-efficacy as "beliefs in one's capabilities to organize and execute the courses of action required to produce given attainments" (p.3). Based on Bandura's description of self-efficacy, it is argued that teacher efficacy is a particular type of self-efficacy specifically related to one's belief in their ability within the context of a teaching profession (Tschannen-Moran et al., 1998).

Teacher self-efficacy has been linked to teacher identity (Luehmann, 2007) and outcomes such as teaching performance and use of teaching strategies (Allinder, 1994; Riggs et al., 1994), job satisfaction (Aldridge \& Fraser, 2016), and ultimately retention or attrition in the profession (Burley, Hall, Villeme, \& Brockmeir, 1991; Glickman \& Tamashiro, 1982; Yost, 2006). Social interactions, such as administrator and collegial acceptance and support, have also been shown to be positively related to teacher self-efficacy, suggesting a connection between teacher social systems and teacher self-efficacy (Aldridge \& Fraser, 2016). These relationships between teacher self-efficacy and other important educational characteristics demonstrate the importance of this construct when considering teacher development. Skaalvik and Skaalvik (2011) studied over 2,500 Norwegian teachers and found that social interactions (i.e., supervisory support, relations with colleagues, and relations with parents) were significant and independent predictors of a sense of belonging to a school community, which ultimately influenced job satisfaction and motivation to remain in the profession. We have previously invoked this community-based sense of belonging as a mechanism for stimulating professional identity and retention that can be promoted in teacher development programs (Polizzi, Jaggernauth, Ray, Callahan, \& Rushton, 2015). Outside of education, the management field has explored relationships within the professional community as a "net or a web in which an individual can become stuck" (p.1104) to improve job satisfaction and limit job turnover (Mitchell, Holtom, Lee, Sablynski, \& Erez, 2001).

\section{Conceptual framework}

SNA provides the methodological tools to outline the interactions that occur within a CoP by providing a visualization of the structural and quantitative characteristics of how individuals interact in a community. In this manuscript, we use SNA to identify key characteristics 
of teacher $\mathrm{CoP}$ networks and relate them to constructs (e.g., self-efficacy and identity) typically associated with other conceptualizations of teacher CoP in the literature. Wenger-Trayner and Wenger-Trayner (2015) draw a distinction between $\mathrm{CoP}$ and broader networks, stating, "A [CoP] is not merely...a network of connections between people" (p.2). Included with this line of thinking is how one CoP can differ from another based on the characteristics of the CoP (i.e., Wenger, 1998). For instance, different academic disciplines (i.e., mathematics and science) would not necessarily have the same characteristics (i.e., domain of knowledge) and one could hypothesize that because of this, their networks could also differ (Wenger, 1998). It is true that a conference networking event or a website for collecting social network contacts would not meet the complex criteria for a $\mathrm{CoP}$ (e.g., sharing practices to strengthen existing knowledge and generate new knowledge over time, among others). However, a case has also been made in the management field to identify existing $\mathrm{CoP}$ and study them as a specific type of social network based on shared occupational practice. For instance, previous work has shown that SNA measures can be associated with improved organizational or community performance (Cross, Laseter, Parker, \& Velasquez, 2006). In this paper, we focus on CoP's in which the shared occupational practice is teaching. We have recently adopted this approach by operationalizing teacher $\mathrm{CoP}$ as individual teacher networks containing contacts for sharing teaching content and/or pedagogy (Polizzi, Ofem, Coyle, Lundquist, \& Rushton, 2019a; Polizzi, Ofem, Coyle, Lundquist, \& Rushton, 2019b). By operationalizing teacher CoP in this way-that is describing and quantifying $\mathrm{CoP}$ as specific social networks based on shared occupational practice, content, and pedagogy - we have previously been able to statistically examine the effect of gender on teacher CoP and overall teacher self-efficacy beliefs (Ofem et al., 2021).

In this work, we are interested in taking steps to further describe teacher $\mathrm{CoP}$ in network terms and empirically connect teacher CoP networks, identity, and selfefficacy. To that end, we examine the feasibility of using teacher CoP in the context of science and mathematics teachers spanning five states and investigate relationships between the factors underlying teacher identity and teacher self-efficacy. Our research is guided by the following research questions:

1. Which features of teacher communities of practice $(\mathrm{CoP})$ can be described and quantified as specific occupational networks related to teaching content and/or pedagogy?

2. How are CoP networks and subfactors of identity and self-efficacy correlated to one another, given that some are individual in nature and others are community based?

3. To what extent do mathematics and science teachers CoP networks, identity, and self-efficacy differ?

4. To what extent are CoP networks related to identity and self-efficacy, and therefore similar to other conceptualizations of CoP?

\section{Methods}

Study design and participants

This study was conducted in the context of a larger project to investigate the relationships between teacher characteristics, including identity and self-efficacy; CoP network properties; and outcomes in retention. The current foundational work focused on relationships between identity, self-efficacy, and CoP network properties. Teachers were recruited to this study if they had recently participated in a preparation program at a higher education institution awarded a Robert Noyce Teacher Scholarship Program grant by the National Science Foundation. Noyce programs were selected from five universities spanning the Midwest, Northeast, and Southeast US. Qualtrics (Provo, UT) online survey links were distributed via email blast to approximately 430 teachers, generating 165 responses. We calculated a completion rate of $38.4 \%$, which represents a minimum rate, given that some email addresses were likely to be unmonitored. Participants reported support from a university teacher preparation program alone $(40 \%)$, or with additional scholarship/stipend financial incentives (60\%), such as scholarship funds and extracurricular professional development via Noyce (nsfnoyce.org) or Woodrow Wilson Fellowship awards (woodrow.org). Participants were predominantly early career teachers with five or less years of teaching completed at the time of the survey $(87 \%)$ or $>5$ years $(13 \%)$, were teaching full time (85\%), identified as science $(78 \%)$ or mathematics $(22 \%)$ teachers, placed in middle $(22 \%)$ or high schools (78\%), spanned ages 20-65, identified as female (58\%), and were White/non-Hispanic (94\%) (Supplemental Figure S1).

\section{Analytic approach}

Our general approach to answering the research questions followed three phases. First, we performed a descriptive statistical analysis of each construct (i.e., network, identity, and self-efficacy) using aggregated mathematics and science teacher data. Next, we performed a comparative statistical analysis of science and mathematics teacher networks, identity, and self-efficacy. Finally, we examined correlations between networks, identity, and self-efficacy to determine which constructs were shared among mathematics and science teachers. 
Teacher CoP network survey and SNA

The teacher network instrument used in this study was based on our previous efforts to describe teacher communities of practice in network terms. We have previously taken an individual teacher-centered (i.e., ego network) approach to understanding how teachers create and interpret the networks related to their craft. We found that teachers reported and discussed interactions with a teaching community that were largely local in nature, and related to their practice (Polizzi et al., 2019a). In an extension of that work, we refined the CoP network survey using cognitive interviews, collected information on the types of contacts (e.g., positive role models), and surveyed perceptions of network structures using images depicting variations in a network structure (Ofem et al., 2021). The diversity of STEM subjects and regions of the country (along with their contextual priorities) present in our sample precluded the stipulation of specific content or specific pedagogical practices being listed in the survey. The images of network structures (Fig. 1), called visual network scales (VNS), are based on the work of Mehra et al. (2014), who refined the images and instruments in other social science contexts (i.e., fraternity/sorority, lab, and small business studies). In the present study, we have used the same CoP instrument as (Ofem et al., 2021). CoP characteristics from this instrument are described below.

\section{Network size}

Participants were prompted via a name generator, "Who do you interact with related to teaching content and/or pedagogy in the in which you work?", and the blank was sequentially replaced with school, district, state, and nation/international. Network size was calculated from the total number of contacts reported, and ranged from 0 to 40 (the maximum number of fields in the survey name generator).

\section{Energizing contacts}

Participants were prompted to "Indicate the degree to which each contact energizes you as a teacher," and each contact from the name generator was displayed, along with a 5-point Likert-style scale from mostly de-energizes (1) to mostly energizes (5). The energizing level for each contact was assigned an integer value 1-5, and then contact values were summed as a measure of positive influence within the network. The summative score was divided by the network size to produce an average network level variable on the 5-point scale. A larger energizing value on the 5-point scale indicates a network that has a higher proportion of energizing contacts whereas a smaller energizing value indicates a network with a higher proportion of de-energizing contacts. For example, a teacher with two contacts [one mostly deenergizing (value $=1$ ) and one mostly energizing (value $=5$ ) would have a summative score of 6 , which if divided

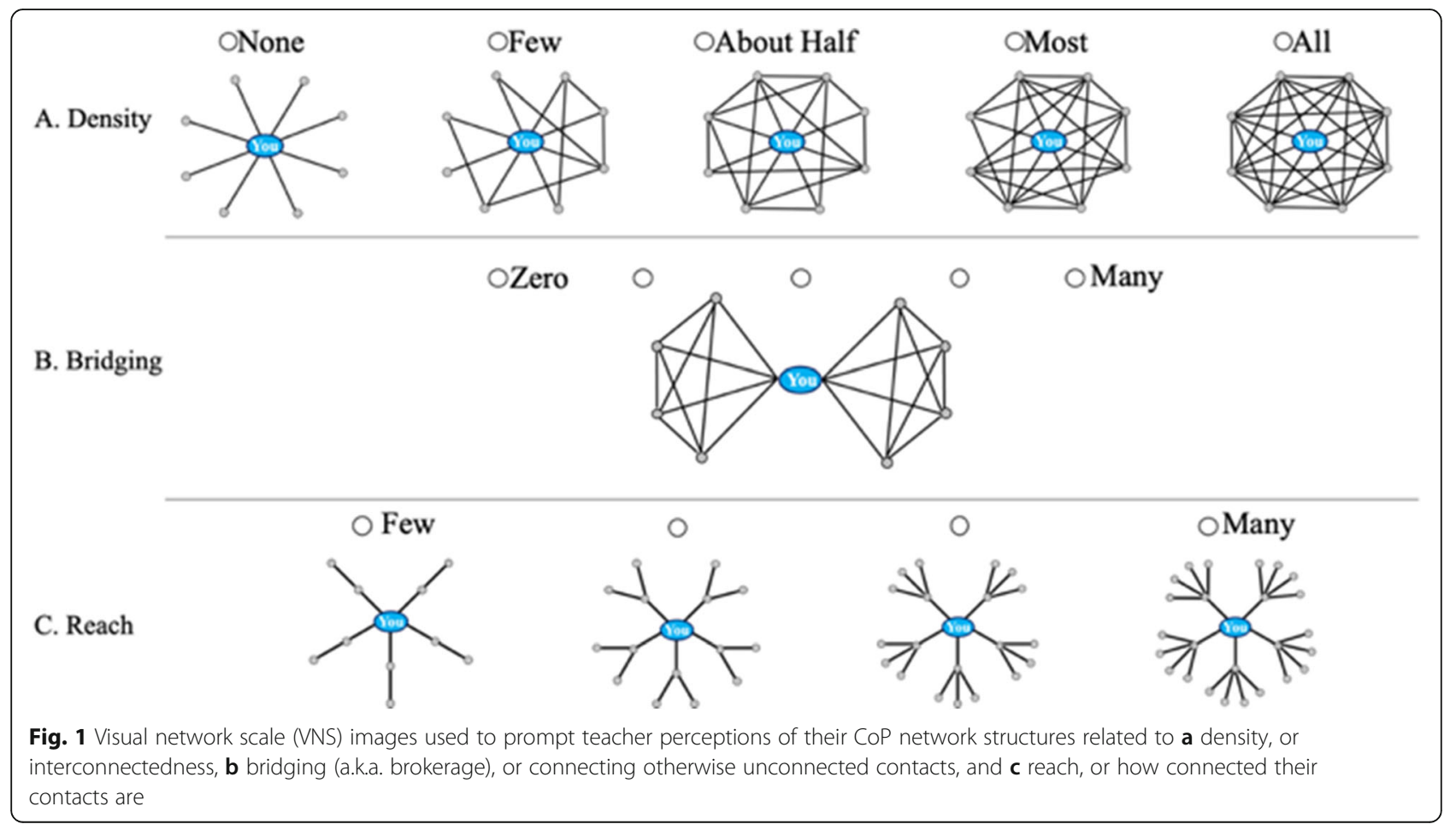


by the network size (2) would yield an average network value of 3 (neutral on the Likert scale). This teacher would be interpreted to have a network that was not more energizing or de-energizing in nature.

\section{Frequency of interaction}

Participants were prompted, "For each contact, indicate the frequency of interactions related to teaching content and/or pedagogy," and each contact from the name generator was displayed along with five options: daily, weekly, monthly, several times a year, once a year. The frequency level for each contact was assigned an integer value 5-1, with daily assigned as 5 and once a year assigned as 1 , and then contact values were summed as a measure of interaction levels within the network. The summative score was divided by the network size to produce an average network level variable on the 5-point scale. A larger frequency value on the 5-point scale indicates a network with more frequent interactions, whereas a smaller frequency value indicates a network with less frequent interactions.

\section{Network density}

Participants were prompted with "In your opinion, which of the network diagrams best approximates the overall degree of interconnectedness in your own network of professional interactions?" and shown the density VNS with five answer options (Fig. 1a). Density was also reported at the separate geographic levels if the teacher reported one or more contacts in the corresponding name generator.

\section{Network bridging}

Participants were prompted with "Using the scale, please rate the extent to which you think you occupy a bridge position in your overall personal network of professional contacts related to teaching content and/or pedagogy," and shown the bridging VNS with five answer options (Fig. 1b).

\section{Network reach}

Participants were prompted with "In your opinion, which of the network diagrams best approximates your overall personal network of professional contacts related to teaching and/or pedagogy?" and shown the reach VNS with four answer options (Fig. 1c). Ordinal variables were generated from the VNS questions for subsequent analyses.

\section{Discipline-based teacher identity instrument}

The teacher identity instrument used in the study is based on the Science Teacher Identity instrument (Chi, 2009). For the purposes of our current study, we were interested in performing an initial exploration of the STI instrument with our target population. Due to the small sample size of this study, we removed all but 18 of the survey items from the original 48 (Supplemental Table S1). These 18 survey items were specifically selected because of their alignment with our conceptual framework and communities of practice characteristics. Due to using part of an instrument, we treated the survey as a new instrument and collected new evidence of validity and reliability. Evidence of face and construct validity was gathered through three expert reviews of the items aligned to our framework and through exploratory factor analysis, respectively (e.g., Reeves \& Marbach-Ad, 2016). Additionally, we calculated new Cronbach alphas for each factor to establish reliability (Santos, 1999). These metrics were then compared with those reported by Chi (2009) for the original survey instrument.

We also administered the survey to self-reported mathematics teachers after replacing the word science in each prompt with math. This modification for math was possible, because the use of identity in the survey was cast in the participant's perception of science or math as a discipline, but was not specific to discipline-specific tasks, such as using the scientific method or mathematical proofs. For each STI item, respondents were asked to indicate agreement using a four-point Likert-style scale ranging from strongly disagree to strongly agree.

\section{Teacher self-efficacy beliefs instrument}

The teacher self-efficacy instrument used in the study was the Teachers' Efficacy Beliefs Systems (TEBS)-Self instrument (Dellinger, Bobbett, Olivier, \& Ellett, 2008). Briefly, Dellinger et al. (2008) reviewed the TEBS-Self instrument with 31 items that were not specific to a teaching discipline, but instead represented core teaching competencies such as classroom management or promoting higher order thinking skills. Dellinger (2001) collected data from 381 teachers, performed a principal component analysis (PCA) with direct Oblimin rotation, and obtained a four-factor solution explaining $61 \%$ of the sample variance. The Dellinger (2001) components were similar to those described by Olivier (2000) $(n=1437$, PCA, Varimax rotation, five-factor solution) and Bobbett (2001) $(n=555$, PCA, Varimax rotation, four-factor solution) despite differences across the studies in sample sizes, data completeness, and the addition of a 31st item on the Dellinger instrument, as was noted in a comparison of the three studies (Dellinger et al., 2008). In the current study, we utilized the 31 item TEBS-Self instrument. For each TEBS-Self item, respondents were asked to indicate agreement using a four-point Likertstyle scale ranging from weak to very strong. 


\section{Statistical analyses}

Data were analyzed in the R software v3.6.1 (RCoreTeam, 2019) to determine appropriateness for exploratory factor analysis (EFA) using Keiser-Meyer-Olkin measure of sampling adequacy and Bartlett's test. EFA, rather than confirmatory factor analysis, was used because our sample was different enough from previously studied populations that the structure of the instruments needed to be reestablished. Mardia's test of skewness and kurtosis indicated our identity and self-efficacy data did not follow multivariate normal distributions. Therefore, we employed principal-axis factoring, as a preferred extraction method when the assumption of multivariate normality is violated (Costello \& Osborne, 2005). Due to underlying correlations between latent constructs, we applied the Oblimin rotation method. A significant factor loading cutoff of 0.45 was chosen in accordance with sample sizes of 160 (Hair, Black, Babin, \& Anderson, 2009). Single items were deleted iteratively from EFA models when low factor loading or cross loading occurred. EFA models were evaluated using a combined approach that leveraged statistical criteria (i.e., Scree test, parallel analysis, and Kaisers rule eigenvalue >1) and ultimately the factor structure was compared to that previously published. Internal reliability was measured by analyzing Cronbach' alphas, and for factors containing only two items, Pearson correlations and Spearman-Brown coefficients were also determined. Analyses of the whole sample and math and science teacher sub-groups were also performed using the $\mathrm{R}$ software. Survey instruments and additional details are available in the Supplemental Materials on the journal website.

\section{Results and discussion}

Teacher communities of practice display distinct network characteristics

Our descriptive analysis began with teacher CoP data and network characteristics. Collectively, science and math teachers reported overall networks averaging 9.8 contacts. Total counts of contacts at each geographic proximity were skewed toward local school $(53 \%)$ and district (22\%) interactions (Fig. 2a), consistent with time and effort required to form relationships and the increased cost to maintain interactions over longer distances. On average, overall frequencies of interaction and levels of energizing contacts were predominantly weekly to monthly (3.6/5) and energizing (4.0/5), respectively. Together, we interpret the local proximity, high frequency, and energizing nature of the interactions related to teaching content and/or pedagogy to support the consideration of $\mathrm{CoP}$ from a network perspective.

Turning to the aggregate network structures provided by the VNS prompts, teachers reported that their overall
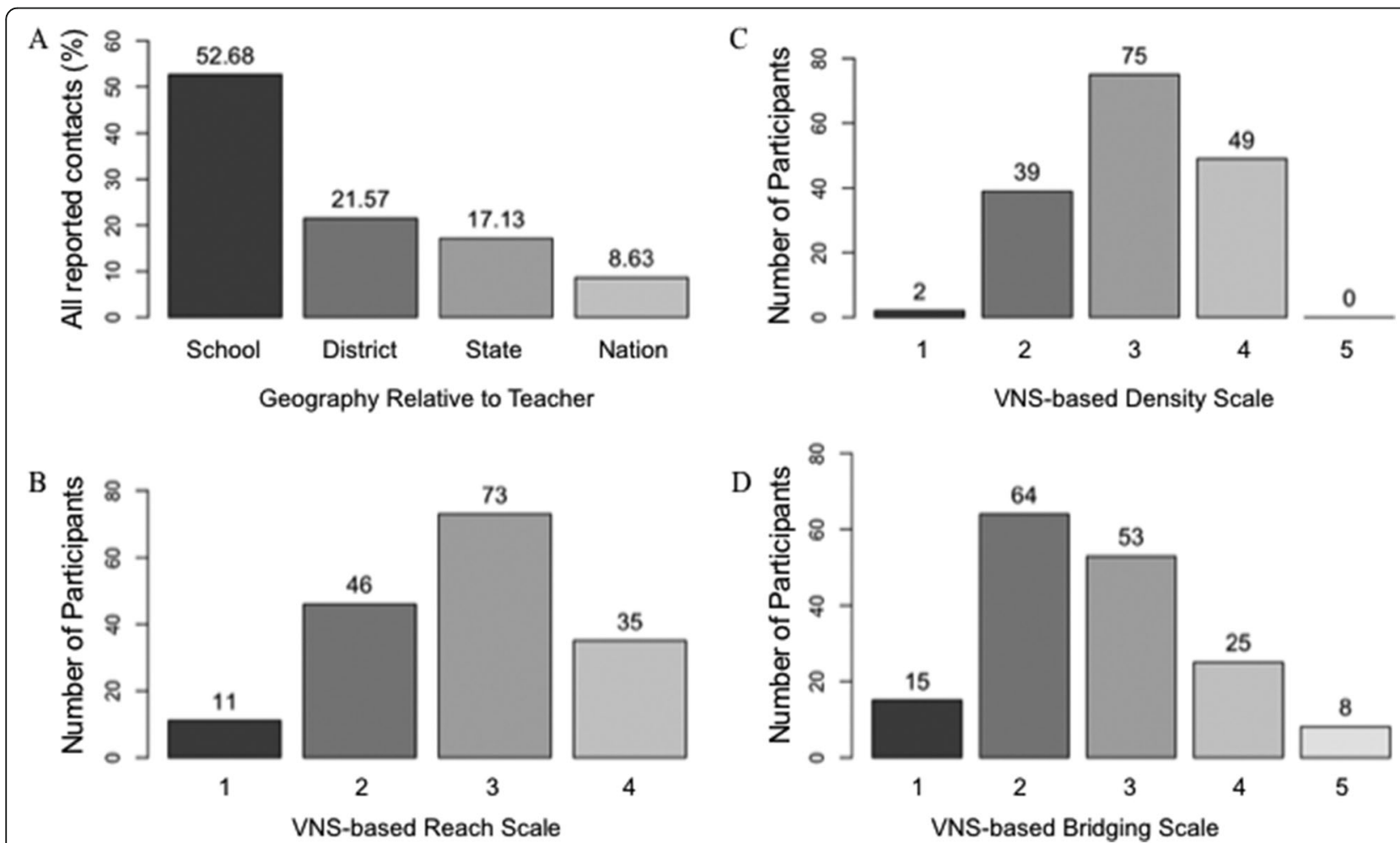

Fig. 2 Science and math teacher CoP network characteristics. Distributions of a all reported contacts disaggregated by geographic proximity to the surveyed teacher and perceptions of overall network $\mathbf{b}$ reach, $\mathbf{c}$ density, and $\mathbf{d}$ bridging based on visual network scale images in Fig. 1. Sample: $n=165$ 
CoP networks had an extended reach (2.8/4), meaning that teachers contacts were perceived to have relatively more of their own contacts (Fig. 2b). A similar pattern emerged for overall network density (3.0/5), with teachers perceiving that their contacts were relatively well connected to each other (Fig. 2c). The pattern for overall network bridging (Fig. 2d) showed a wider distribution than density, but also averaged higher than the midpoint of the scale (2.7/5). This finding highlights a key difference between network characteristics determined by VNS and those calculated from whole networks, in that participants can perceive mutually exclusive network structures. In a whole network calculation, having higher density necessitates lower bridging; however, in our aggregate sample, the perceived density and perceived bridging were both elevated on average (i.e., > 2.5/5).

\section{Teacher identity includes individual and community factors}

EFA of the discipline-based identity data revealed support for both four- and five-factor solutions. The fivefactor solution was supported by parallel analysis, a preferred statistical metric for selecting an EFA solution, but grouped the 18 items into fine slices, with no factor having more than three items, and three factors having only two items. Further examination of the items in the groupings showed that the five-factor solution loaded items from factors that were distinct in previous uses of the instrument, such as Knowledge \& Skills together with Social Respect.

A four-factor solution (Table 1) was supported by a Scree test (Supplemental Figure S2), Kaiser's rule (eigenvalue $>1$ ), and theoretical underpinnings. In the fourfactor solution, one factor contained six items, and while two factors contained only two items each, those factors showed acceptable (Cronbach's alpha $>.7$ ) or higher levels of internal reliability in the aggregate sample (Supplemental Table S2) as compared to those reported by Chi (2009). The four-factor solution accounted for $63.1 \%$ of the sample variance. Ultimately, we determined the most parsimonious EFA model was the four-factor solution, which we selected for additional analyses.

The Self-Image (SI) factor contained the greatest number of items (i.e., 6) and the highest internal reliability (i.e., Cronbach's $\alpha=.89$ ) compared to the other factors in the solution. Items within this factor mapped to Chi's (2009) dimensions of Intrinsic Satisfaction (i.e., Cronbach's $\alpha=.81$ ) and Belief \& Value (i.e., Cronbach's $\alpha=$ .61). The SI factor included three items with disciplinebased identity information [e.g., "I truly enjoy being a math (or science) teacher] and three items with more general teacher identity information (e.g., "Working with students has its costs, but it's worth it").

Also consistent with Chi's (2009) report, our EFA separated the "community practice" items into two distinct factors (Supplemental Table S1), which we labeled Community Action (CA) and Community Value (CV). The CA factor contained three items, including actions within the teaching community, such as "I frequently talk to colleagues about teaching science (or math)." (i.e., Cronbach's $\alpha=.76$ ). The CV factor contained two items that including a value statement of community practice, such as "It is helpful to be able to discuss the progress of students with colleagues." (i.e., Cronbach's $\alpha=.73$ ). For $\mathrm{CA}$, teachers were prompted to determine if they engaged in the teaching community, while for $\mathrm{CV}$, teachers reported the value of engaging. While Chi (2009) did not make this distinction, instead referring to the factors as Community Practice 1 and Community Practice 2 (i.e., Cronbach's $\alpha=.74$ ), it may explain why an item intended for the Belief \& Value subscale cross-loaded on Community Practice 2 (i.e., what we labeled Community Value) and was removed from Chi's (2009) analysis. The fourth factor in our EFA model, Social Respect (SR), loaded two items related to external appreciation and recognition (i.e., Cronbach's $\alpha=.76)$. This was considered acceptable given Chi (2009) found SR to have a Cronbach's alpha score of .62. Given the low number of items in the SR and CV factors, we also evaluated these subscales using Pearson correlations and SpearmanBrown coefficients, which supported internal agreement.

Table 1 Summary of the identity exploratory factor analysis

\begin{tabular}{|c|c|c|c|c|}
\hline Factor $^{a}$ & No. of items & Variance explained (\%) & $a^{\mathbf{b}}$ & Questionnaire items \\
\hline Identity overall & 13 & 63.1 & 0.868 & All of below \\
\hline 1. SI: Self-image & 6 & 29.0 & 0.893 & $13,14,15,16,17,18$ \\
\hline 2. CA: Community action & 3 & 13.2 & 0.756 & $3,4,5$ \\
\hline 3. SR: Social respect ${ }^{c}$ & 2 & 10.8 & 0.756 & 10,11 \\
\hline 4. CV: Community value ${ }^{c}$ & 2 & 10.1 & 0.727 & 6,7 \\
\hline
\end{tabular}

Items 1, 2, 8, 9, and 12 were deleted due to low factor loadings or mixed loadings. Sample: $n=165$

${ }^{\mathrm{b}}$ Cronbach's alpha coefficient: $>0.9$ excellent; $>0.8$ good; $>0.7$ acceptable

'Factors with only two items were further analyzed. Pearson correlation for two items in $\mathrm{SR}$ is $0.609, p$ value $<.001$, for two items in CV is $0.574, p$ value $<.001$. Spearman-Brown coefficient for SR is 0.757 , for CV is 0.729 
Having identified factors and items describing identity, we generated scores for each factor by assigning values to the Likert-style scale and summing a teacher's responses to each associated item. We also tested an overall identity construct summarizing all the factor items (Supplemental Table S3). Both identity factor scores and overall identity scores were then used in subsequent comparative statistical analyses.

Teacher self-efficacy beliefs include four classroom factors The next step in our analysis was to examine science and math teacher self-efficacy beliefs. The TEBS-Self instrument has previously been used with slight variations in data completeness and item number, as reviewed by Dellinger et al. (2008). Therefore, we performed our own EFA on data representing the full 31 items and complete data. Analysis of the aggregate data revealed the most parsimonious EFA model was a four-factor solution supported by Scree test (Supplemental Figure S3), parallel analysis, and general alignment with Dellinger et al.'s (2008) constructs of Management/Climate; Higher Order Thinking Skills; Planning, Accommodating for Individual Differences; and Communication/Clarification (Supplemental Table S4). The EFA model accounted for $62.7 \%$ of the sample variance and showed good (Cronbach's alpha >0.8) or excellent levels of consistency within each factor (Table 2, Supplemental Table S5).

Having identified factors and items describing selfefficacy, we generated scores for each factor by assigning values to the Likert-style scale and summing a teacher's responses to each associated item. We also tested an overall self-efficacy construct summarizing all the factor items (Supplemental Table S6). Both self-efficacy factor scores and overall self-efficacy scores were then used in subsequent comparative statistical analyses.

\section{Teaching discipline is a contributor to CoP network characteristics}

Among the aspects of teacher $\mathrm{CoP}$ that we measured were types of perceived structural features (i.e., size, density, bridging, and reach), interactions (i.e., frequency), and contacts (i.e., energizing). Comparisons across science and math revealed significant differences in CoP network structures (Table 3). Math teachers were significantly more likely to report smaller network sizes $(p<.05)$, averaging 8.0 contacts per network, compared with science networks averaging 10.4 contacts. Math teachers also reported significantly fewer bridging opportunities in their networks $(p<.01)$. Beyond the CoP structural features, only the frequency of interactions variable $(p=.09)$ approached the significance level cutoff. In this instance, math teachers reported higher average interaction frequencies shifted toward weekly interactions with their contacts, compared to relatively less frequent monthly interactions in science networks.

We also noted that benefits could be derived from the CoP network features that were statistically similar across science and math. For example, reach and density are features indicative of well-connected contacts, and contacts who are well-connected to each other, respectively. Similarity across disciplines suggested that both groups perceive being well connected with contacts for teaching content and/or pedagogy. Both groups also reported average levels of energizing contacts on the positive end of the Likert scale, suggesting the cultivation of CoP members with positive outlooks on honing their shared craft.

While not correlative in nature, the initial pattern of individual network characteristics suggests broader differences in $\mathrm{CoP}$ across disciplines. On average, math CoP appeared to favor smaller network sizes with more frequent interactions, and fewer bridging links to unique contacts and information. In contrast, science CoP appeared to favor larger networks with less frequent interactions, but more bridging links to novel resources. Still, both groups reported to find their respective $\mathrm{CoP}$ arrangements to be energizing in nature.

\section{Discipline-based identity is a useful construct for both science and math teachers}

To our knowledge, use of the discipline-based teacher identity instrument has not been reported in other STEM teacher populations. Therefore, after evaluating the factor pattern in our aggregate dataset, we

Table 2 Summary of the self-efficacy beliefs exploratory factor analysis

\begin{tabular}{lllll}
\hline Factor $^{\mathbf{a}}$ & No. of items & Variance explained (\%) & $\boldsymbol{a}^{\mathbf{b}}$ & TEBS-Self items $^{\mathbf{c}}$ \\
\hline Self-efficacy overall & 23 & 62.7 & 0.955 & All of below \\
1. CM & 9 & 22.4 & 0.926 & $4,6,7,8,9,24,26,30,31$ \\
2. HOTS & 5 & 16.3 & 0.901 & $14,19,20,21,25$ \\
3. PAID & 4 & 11.7 & 0.846 & $1,2,27,28$ \\
4. CC & 5 & 12.3 & 0.869 & $5,10,16,17,18$ \\
\hline
\end{tabular}

a Abbreviations: Climate/Management (CM), Higher Order Thinking Skills (HOTS), Planning, Accommodating for Individual Differences (PAID), Communication/ Clarification (CC). Sample: $n=165$

${ }^{\mathrm{b}}$ Cronbach's alpha coefficient: $>0.9$ excellent; $>0.8$ good

Items $3,11,12,13,15,22,23$, and 29 were deleted due to low factor loadings or mixed loadings 
Table 3 Differences in science and math teacher CoP network characteristics by the mean

\begin{tabular}{|c|c|c|c|c|}
\hline CoP network characteristics & Math teacher mean (SD) & Science teacher mean (SD) & Difference mean (math-science) & $p$ value \\
\hline Network variables ${ }^{a}$ & - & - & - & - \\
\hline Network size & $8.00(4.74)$ & $10.35(6.74)$ & -2.35 & $.034^{*}$ \\
\hline Density & $3.03(0.74)$ & $3.04(0.77)$ & -0.01 & .983 \\
\hline Bridging & $2.31(0.89)$ & $2.78(1.01)$ & -0.48 & $.008^{* *}$ \\
\hline Reach & $2.69(0.79)$ & $2.83(0.87)$ & -0.14 & .348 \\
\hline Frequency $^{\mathrm{b}}$ & $3.71(0.73)$ & $3.51(0.71)$ & 0.19 & .094 \\
\hline Energizing $^{\mathrm{b}}$ & $4.07(0.52)$ & $3.99(0.64)$ & 0.08 & .552 \\
\hline
\end{tabular}

${ }^{a}$ Characteristics at the overall network level

${ }^{b}$ Frequency of interactions and energizing nature of contacts are the average across all contacts in each network. 6 teachers reporting 0 contacts were excluded from analysis. Sample $n=159$ (math $n=34$; science $n=125$ )

${ }^{c} p$ values for differences are from Wilcoxon rank sum test, which is identical to Mann-Whitney $U$ test. Unless otherwise stated, sample $n=165$ (math $n=36$; science $n=129)$. Significance: $p<0.05(*) ; p<.01(* *)$

investigated the extent to which the identity data differed for science and math teachers. First, we disaggregated the sample by discipline, and examined differences between science and math by comparing the factor scores of the two groups directly. Since the Shapiro-Wilk test indicated our data from the math population did not follow a normal distribution, we used a Wilcoxon rank sum test instead of two sample $t$ test. Although math teachers generally reported lower discipline-based identity scores, our analysis indicated no significant difference at the $p<.05$ level (Table 4). However, we did observe that the overall identity score approached this cutoff $(p=.086)$ with a strong contribution from the Self-Image identity factor $(p=.088)$. This suggested significant differences at the item level, if not the factor level. To be thorough, we further investigated differences in Self-Image responses. We found that responses to 3 of the 6 items within the Self-Image factor were significantly different between science and math teachers (Table 5), with math teachers consistently reporting lower identity scores on each item within the factor (Supplemental Figure S4). We noted that the significant differences (i.e., on items $15,16,17 ; p<.05$ ) included items from both general teacher identity (i.e., items 13, 14, 16) and discipline-specific identity (i.e., items $15,17,18)$. The difference could not be accounted for when controlling for different teacher preparation sites (Supplemental Figure S5, Supplemental Table S7).
Overall, this suggests greater challenges for math teachers and math teacher identities, relative to science, and that those challenges may extend beyond teaching math content.

\section{Self-efficacy beliefs vary by discipline for promoting higher order thinking skills}

Of the 23 items emerging from the self-efficacy EFA model, none reference a specific discipline. However, the Higher Order Thinking Skills factor does reference skills important to cultivate in science and math students. Items 19 and 21 prompted, respectively, for teacher confidence in abilities to "Actively involve students in developing concepts," and "Actively involve students in critical analysis and/or problem solving." In order to examine differences between science and math teacher TEBS-Self scores, we performed a comparative analysis similar to identity above. We found that while math teachers reported lower overall TEBS-Self scores than science teachers (Table 6), only the Higher Order Thinking Skills factor scores were significantly lower $(p<.05)$.

The lower self-efficacy scores reported by math teachers provide additional evidence that the challenges facing math teacher populations may differ from science teachers. It is possible that societal norms perpetuate that "math is hard" (Ashcraft, Krause, \& Hopko, 2007) while conversely there is popular sentiment that science can solve global problems (Gates, 2020), and this could

Table 4 Differences in science and math teacher identity characteristics by the mean

\begin{tabular}{lllll}
\hline Identity characteristics & Math teacher mean (SD) & Science teacher mean (SD) & Difference mean (math-science) & $\boldsymbol{p}$ value \\
\hline Identity overall $^{\mathbf{b}}$ & $42.89(7.50)$ & $45.12(5.38)$ & -2.23 & .086 \\
SI & $19.56(4.67)$ & $21.11(3.10)$ & -1.55 & .088 \\
CA & $9.25(2.25)$ & $9.74(2.17)$ & -0.49 & .195 \\
SR & $6.67(1.43)$ & $6.82(1.17)$ & -0.16 & .732 \\
CV & $7.42(1.16)$ & $7.45(0.85)$ & -0.04 & .831 \\
\hline
\end{tabular}

adentity EFA factors: Self-Image (SI); Community Action (CA); Social Respect (SR); Community Value (CV)

${ }^{\mathrm{b}} p$ values for differences are from Wilcoxon rank sum test, which is identical to Mann-Whitney $U$ test. Unless otherwise stated, sample $n=165$ (math $n=36$; science $n=129$ ) 
Table 5 Comparison of science and math teacher scores on items within the self-image factor

\begin{tabular}{|c|c|c|c|c|c|c|}
\hline Item & & $\begin{array}{l}\text { Math } \\
\text { median }\end{array}$ & $\begin{array}{l}\text { Math } \\
\text { mean }\end{array}$ & $\begin{array}{l}\text { Science } \\
\text { median }\end{array}$ & $\begin{array}{l}\text { Science } \\
\text { mean }\end{array}$ & $p$ value $^{a}$ \\
\hline 13 & The quality of my teaching contributes to my career advancement. & 3 & 3.03 & 3 & 3.12 & .268 \\
\hline 14 & $\begin{array}{l}\text { I find it satisfying to think that I am contributing to the profession } \\
\text { by teaching. }\end{array}$ & 3.5 & 3.31 & 4 & 3.48 & .182 \\
\hline 15 & I truly enjoy being a [math/science] teacher. & 4 & 3.28 & 4 & 3.66 & $.011^{*}$ \\
\hline 16 & Working with students has its costs, but it's worth it. & 4 & 3.33 & 4 & 3.68 & $.010^{*}$ \\
\hline 17 & [Math/science] teaching is a very rewarding job. & 3 & 3.19 & 4 & 3.55 & $.017^{*}$ \\
\hline 18 & I find satisfaction in my own development as a [math/science] teacher. & 4 & 3.42 & 4 & 3.62 & .140 \\
\hline
\end{tabular}

${ }^{\mathrm{a}}$ One-sided $p$ values of Wilcoxon rank sum test (Null hypotheses: the scores of math teachers are less than science teachers). Sample: $n=165$. Significance: ${ }^{*} p$ $<.05$

negatively impact identifying as a math teacher or feeling effective in the math classroom. Similarly, US testing requirements in language arts and math related to No Child Left Behind legislation may disproportionately put math teachers at odds with the teaching and assessment strategies they would like to enact, since these constraints are not as prevalent in science subjects. Furthermore, recent US initiatives related to the Next Generation Science Standards are explicit about trying to develop higher order thinking skills in students, which may account for higher perceived self-efficacy in this area in science teachers, even if this is only partly due to concept recognition rather than actual gains in efficacy. Although the causal nature of the differences was not apparent in data from this study, our analysis of math/science teachers was consistent with published uses of the TEBS-Self instrument in mixeddiscipline teacher populations.

\section{Self-efficacy is correlated with the individual and community factors of identity}

In the final phase of our analysis, we examined correlations between the teacher variables in our aggregate sample (Table 7). We observed positive correlations within factors from the identity instrument $(\rho=.17$ $.47 ; p<.05)$ and strong positive correlations within factors from the self-efficacy instrument $(\rho=.53-.71 ; p<$ $.01)$. These findings support the examination of overall identity and overall self-efficacy variables, respectively. Overall identity was significantly correlated with overall self-efficacy $(0.48 ; p<.01)$, consistent with published relationships between these two constructs.

Correlations between the self-efficacy and identity factors provided additional details of the relationship. For example, we observed that all four self-efficacy factors were relatively strongly correlated with the SI identity factor $(\rho$ $=.33-.46 ; p<.01)$. The self-efficacy factors described teaching activities that are likely to be recognized inside and outside of the profession, such as keeping students on task, trying to improve achievement, and communicating information to diverse students. The positive correlation with SI suggests that if a teacher believes they can perform those teaching activities, they are more likely to see themselves as an individual teacher, and find teaching rewarding. At the same time, the inability to manage student differences, classroom climates, and achievement outcomes is likely to move their image of themselves further outside the identity of an ideal math or science teacher. This supports a strong link between belief in teaching selfefficacy and belief in individual teacher identity.

We also observed that all four self-efficacy factors were relatively strongly correlated with the $\mathrm{CA}$ identity factor ( $\rho=.32-.45 ; p<.01)$. The CA factor included acting as part of the science/math community and identifying as belonging to groups of professional math/science teachers. The positive correlation with self-efficacy factors suggests that believing in personal abilities to perform in the classroom is also important for an identity positioned within the larger profession of teaching and

Table 6 Differences in science and math teacher self-efficacy characteristics by the mean

\begin{tabular}{lllll}
\hline Self-efficacy characteristics & Math teacher mean (SD) & Science teacher mean (SD) & Difference mean (math-science) & $\boldsymbol{p}$ value \\
\hline Self-efficacy overall $^{\mathbf{a}}$ & $62.67(12.36)$ & $65.92(13.29)$ & -3.26 & .201 \\
CM & $24.61(5.94)$ & $26.52(5.78)$ & -1.90 & .105 \\
HOTS & $12.86(3.45)$ & $14.20(3.49)$ & -1.34 & $.041^{*}$ \\
PAID & $10.56(2.50)$ & $10.35(2.61)$ & 0.21 & .508 \\
CC & $14.64(3.03)$ & $14.86(3.19)$ & -0.22 & .655 \\
\hline
\end{tabular}

${ }^{a}$ Self-efficacy EFA factors: Management/Climate (CM); Higher Order Thinking Skills (HOTS); Planning, Accommodating for Individual Differences (PAID); Communication/Clarification (CC)

${ }^{\mathrm{b}} p$ values for differences are from Wilcoxon rank sum test, which is identical to Mann-Whitney $U$ test. Unless otherwise stated, sample $n=165$ (math $n=36$; science $n=129)$. Significance: $p<0.05(*)$ 
Table 7 Spearman correlations among science and math identity, self-efficacy, and CoP network characteristics

\begin{tabular}{|c|c|c|c|c|c|c|c|c|c|c|c|c|c|c|c|c|}
\hline Variables $^{\mathrm{a}}$ & 1 & 2 & 3 & 4 & 5 & 6 & 7 & 8 & 9 & 10 & 11 & 12 & 13 & 14 & 15 & 16 \\
\hline 1. Identity overall & - & $0.83^{* *}$ & $0.81^{* *}$ & $0.44^{* *}$ & $0.54^{* *}$ & $0.48^{* *}$ & $0.44^{* *}$ & $0.38^{* *}$ & $0.39^{* *}$ & $0.43^{* *}$ & $0.20^{*}$ & 0.11 & $0.26^{* *}$ & $0.20^{*}$ & -0.09 & $0.32^{* *}$ \\
\hline 2. SI & & - & $0.47^{* *}$ & $0.20^{*}$ & $0.28^{* *}$ & $0.45^{* *}$ & $0.46^{* *}$ & $0.37^{* *}$ & $0.36^{* *}$ & $0.33^{* *}$ & 0.09 & 0.09 & $0.17^{*}$ & $0.18^{*}$ & -0.04 & $0.30^{* *}$ \\
\hline 3. $C A$ & & & - & $0.23^{* *}$ & $0.46^{* *}$ & $0.42^{* *}$ & $0.36^{* *}$ & $0.34^{* *}$ & $0.32^{* *}$ & $0.45^{* *}$ & $0.31^{* *}$ & 0.14 & $0.30^{* *}$ & $0.20^{*}$ & -0.15 & $0.24^{* *}$ \\
\hline 4. $S R$ & & & & - & $0.17^{*}$ & 0.11 & 0.05 & 0.09 & 0.14 & $0.16^{*}$ & -0.02 & -0.01 & 0.08 & -0.05 & -0.07 & 0.08 \\
\hline 5. CV & & & & & - & $0.24^{* *}$ & $0.21^{* *}$ & 0.15 & $0.17^{*}$ & $0.27^{* *}$ & 0.12 & 0.07 & 0.12 & $0.17^{*}$ & 0.07 & $0.25^{* *}$ \\
\hline 6. Self-efficacy overall & & & & & & - & $0.92^{* *}$ & $0.86^{* *}$ & $0.73^{* *}$ & $0.84^{* *}$ & 0.10 & 0.06 & $0.16^{*}$ & 0.10 & -0.05 & $0.18^{*}$ \\
\hline 7. $\mathrm{CM}$ & & & & & & & - & $0.71^{* *}$ & $0.60^{* *}$ & $0.69^{* *}$ & 0.09 & 0.08 & 0.15 & 0.07 & -0.03 & $0.17^{*}$ \\
\hline 8. HOTS & & & & & & & & - & $0.55^{* *}$ & $0.66^{* *}$ & 0.09 & 0.07 & 0.15 & 0.11 & 0.00 & 0.13 \\
\hline 9. PAID & & & & & & & & & - & $0.53^{* *}$ & 0.07 & 0.05 & $0.22^{* *}$ & 0.14 & -0.01 & 0.14 \\
\hline 10. CC & & & & & & & & & & - & 0.11 & 0.02 & 0.08 & 0.09 & -0.15 & 0.15 \\
\hline 11. Network size & & & & & & & & & & & - & 0.03 & $0.30^{* *}$ & $0.23^{* *}$ & $-0.35^{* *}$ & 0.13 \\
\hline 12. Density & & & & & & & & & & & & - & 0.03 & $0.28^{* *}$ & 0.04 & $0.18^{*}$ \\
\hline 13. Bridging & & & & & & & & & & & & & - & 0.10 & -0.14 & 0.09 \\
\hline 14. Reach & & & & & & & & & & & & & & - & $-0.18^{*}$ & $0.18^{*}$ \\
\hline 15. Frequency & & & & & & & & & & & & & & & - & 0.10 \\
\hline 16. Energizing & & & & & & & & & - & & & & & & & - \\
\hline
\end{tabular}

${ }^{a}$ Abbreviations: Self-Image (SI), Community Action (CA), Social Respect (SR), Community Value (CV), Management/Climate (CM), Higher Order Thinking Skills (HOTS), Planning Accommodating for Individual Differences (PAID), Communication/Clarification (CC). Sample: $n=159$. Significance: ${ }^{*} p<0.05 ;{ }^{* *} p<0.01$

belonging to a teaching community. Confidence in teaching activities is therefore importantly related to both personal identity and community identity. What is not clear from the current data is the directionality of the interaction and to what extent being part of the teaching community (and having access to community resources) informs confidence in one's abilities to perform locally as a teacher.

The relationship between the self-efficacy factors and the SR factor is relatively weaker than those described above. While SI and CA involve identity based within a teacher or within a teacher group, respectively, the SR factor involves identity based on an external evaluation of the teacher. Specifically, the SR factor includes the importance of being acknowledged by others and recognized by others. A lower correlation between confidence in teaching activities and teacher identity can be rationalized in that context. Teaching can be a thankless job, and confidence in one's teaching abilities, or execution of those abilities, may not be recognized or lauded by external stakeholders. Ultimately, the data suggest that external validation by non-teachers may not be most impactful on teachers' beliefs in their own abilities to perform in the classroom. Instead, self-awareness of teaching and acknowledgement from a teaching community may be more important for teaching confidence.

Previous studies have examined identity and self-efficacy as separate but related constructs (Saka, Southerland, Kittleson, \& Hutner, 2013; Schepens, Aelterman, \& Vlerick, 2009; Settlage, Southerland, Smith, \& Ceglie,
2009) or as hierarchical constructs with self-efficacy as a component of a broader identity (Berger \& Lê Van, 2018; Canrinus, Helms-Lorenz, Beijaard, Buitink, \& Hofman, 2011, 2012). Our correlation data is consistent with a positive, significant relationship between teacher self-efficacy and identity. Exemplifying this relationship, when differences existed in the data, math teachers reported both lower self-efficacy and identity scores, when compared to science teachers. However, our data further support that self-efficacy should not be used as a complete proxy or replacement for identity in research studies, since the portion of teacher identity founded in social respect was not strongly correlated with components of self-efficacy. Instead, our quantitative findings are more consistent with previous hierarchical models that treat self-efficacy as a component of identity. Specifically, teacher selfefficacy appears well aligned with personal and community-based portions of a teacher's identity, such as Gee's (2000) perspective on N-, I-, and Aidentities, but does not account for broader views of teacher identity that include how other external parties view the teacher, such as Gee's (2000) perspective on discourse identity, which relies on recognition by others.

\section{CoP networks correlate with both individual and community aspects of teacher identity}

Similar to the correlations between identity and selfefficacy factors, multiple significant correlations existed 
between identity and $\mathrm{CoP}$ variables (Table 7). The CA identity factor was correlated with the largest number of CoP network features: network size $(0.31 ; p<.01)$, energizing nature of networks $(0.24 ; p<.01)$, and perceived bridging $(0.30 ; p<.01)$ and reach $(0.02 ; p<.05)$. Since CA identity is grounded in action within the teaching community, it may seem intuitive that teacher identity increases as the CoP network increases in size and positive influence. Interestingly, increases in $\mathrm{CoP}$ density and the frequency of interactions within the $\mathrm{CoP}$ did not reinforce CA. Instead, there was a stronger correlation with broader, more open network features, suggesting that access to more novel teaching contacts is more important for identity within the community than increased interactions with fewer redundant contacts. The $\mathrm{CV}$ identity factor was also correlated with energizing contacts $(0.25 ; p<.01)$ and perceived reach $(0.17 ; p<$ $.05)$, further suggesting the value of disciplinary community-based identity is derived from positive influencers and access to broader networks.

The two remaining identity factors, SI and SR, are related to individual identity and identity conferred by outside parties, respectively, and do not intuitively have to be linked to CoP structures. Still, SI was correlated with energizing networks $(0.30 ; p<.01)$ and, to a lesser extent, perceived bridging $(0.17 ; p<.05)$ and reach $(0.18 ; p$ $<.05)$. This may suggest that personal teacher identity (e.g., I am a science/math teacher) can be influenced separately from community-based teacher identity (e.g., $I$ am a member of a certain math/science teacher organization) by positive CoP interactions, with implications that personal identity may persist even as organizational affiliations or contentment change. Turning to SR, we observed no significant correlations with CoP network features, indicating this component of identity may reside outside of the CoP networks we sampled, similar to our self-efficacy result.

\section{CoP networks are correlated with fewer aspects of teacher self-efficacy in the classroom}

Despite multiple correlations between self-efficacy and identity, and identity and CoP, we did not observe many direct correlations between self-efficacy and CoP characteristics (Table 7). The strongest correlation existed between self-efficacy in Planning and Accommodating for Individual Differences and perceived bridging in $\mathrm{CoP}$ networks $(0.22 ; p<.01)$. Network bridging and brokerage have been discussed as facilitating access to novel information and creation of new ideas (Burt, 2000, 2004), when compared to more dense networks where there may be conformity in ideas (Marsden, 1987). In this light, teachers perceiving they occupy more bridging roles may have higher self-efficacy in meeting the challenges of diverse student needs and personalized learning plans, because they have access to more diverse sources of information and social resources. Alternatively, the correlation might be explained in the action of occupying a bridging position. Individuals and groups that are bridged by the teacher are likely to be diverse or varied, and the ability of the bridging teacher to navigate the differences may translate to navigating the diverse needs of students. Given the correlations between $\mathrm{CoP}$ bridging and components of self-efficacy and identity, future studies may be needed to understand the nature of brokerage in teacher $\mathrm{CoP}$ and who or what is being bridged.

\section{Limitations}

This study may have limitations in generalization, given the sample sizes for science and math teachers, and other professional development activities the teachers engaged in at their local levels. It was not our design to control for these additional variables, although when considering alternative interpretations, we did exclude that teacher preparation/placement sites unduly influenced the lower math teacher scores. In addition, our study was part of a larger project, and only considered data from a subset of available survey items and associated variables, leaving room for future studies to explore other dimensions of discipline-based teacher identity, self-efficacy and CoP networks. Furthermore, the subset of survey items used in this study do not include each factor in the originally published instrument (Chi, 2009); therefore, findings are limited to the factors identified through this study and not teacher identity more broadly. Our sample size did not allow for CFA to further refine construct validity; therefore, we presented both latent EFA factors and overall identity and selfefficacy constructs for comparison. This allowed the examination of relationships between $\mathrm{CoP}$ network features, identity, and self-efficacy beliefs, even though there are many other teacher characteristics that might be important to teacher development and education stakeholders (e.g., coursework, strong network ties). We note that we employed several of many available methods for determining network characteristics. We opted for an ego-network approach rather than a wholenetwork approach, in order to focus on what different teachers across the USA were like instead of what a limited number of school or district networks could tell us about every teacher. Ego network data were selfreported, which is a standard practice in SNA, and therefore represent a snapshot of a network in time, rather than collecting electronic email or phone data over a period of time and recreating networks. Network structures were assessed using VNS images of networks, which indicate a personal perception of a network structure, and may deviate from a network structure 
calculated from other secondary tie or whole network methods. Correlations invoking network structures would therefore be between a perception of a network and another variable, so interventions aimed at affecting the network structure would also need to consider that changing a mental model of a network (e.g., professional development to leverage existing resources and networks) may be different than creating actual connections (e.g., assigning mentors or groups). The nature of our correlation analysis precluded the assignment of a direction in the interaction, such that data do not inform whether CoP predominantly drives identity, or vice versa, or if there is a reflexive relationship. Our correlation data also limit the determination of causal relationships. However, our intent with this study is to demonstrate the utility of CoP networks in this STEM context. It is our hope that these constructs could then be used by others in large-scale comparisons relevant to teacher development and desired professional outcomes (e.g., retention and effectiveness). Furthermore, the study is also limited by the nature of the analytical approach used for understanding a CoP. We recognize that while a $\mathrm{CoP}$ is relational in nature (Wenger, 1998), there are more characteristics which define a $\mathrm{CoP}$ (i.e., knowledge and practices). In this study, we sought to capture the relational nature of teachers' $\mathrm{CoP}$ to better understand the structural characteristics rather than both structural and functional.

\section{Conclusions and implications}

Overall, our analysis indicates conceptualizing $\mathrm{CoP}$ as networks is a useful tool for evaluating science and math teachers and investigating other teacher characteristics. A correlation analysis with identity and self-efficacy reveals multiple significant relationships between the constructs and their components. This is consistent with literature linking qualitative conceptualizations of communities of practice to identity and self-efficacy. Still, $\mathrm{CoP}$ network characteristics were more aligned with identity than self-efficacy, despite high correlations between identity and self-efficacy. This may be explained, in part, by the local classroom nature of self-efficacy, while our CoP and identity constructs spanned the classroom and broader communities. The broader nature of $\mathrm{CoP}$ and identity may also help explain earlier reports in the literature that identity and sense of commitment to the teaching community may persist, even when conflicts with a local institution arise. Local conflicts may impact situational self-efficacy, but aspects of community and identity positioned outside the institution can anchor a more firm commitment.

The relationships between the activities of a teacher, the interactions of a teacher, and the identity of a teacher may provide a means to probe the discipline- specific identity via more concrete aspects of practice and teaching community. Specifically, teacher educators aiming to foster strong teacher identities could develop pre-service activities within an explicit, energizing community of practice to promote confidence in diverse teaching activities within the self-efficacy domains we surveyed: classroom management, higher order thinking skills, accommodating individual differences, and clarifying information for students. An overall teacher identity could be enhanced by assessing and addressing weaknesses within those domains and comparison with the community. Alternatively, education researchers seeking to track teacher identity, or relate the abstract identity construct to positive outcomes (e.g., effectiveness or persistence), could probe or observe teacher confidence in these domains and the communities of practice they cultivate.

\section{Supplementary Information}

The online version contains supplementary material available at https://doi. org/10.1186/s40594-021-00275-2.

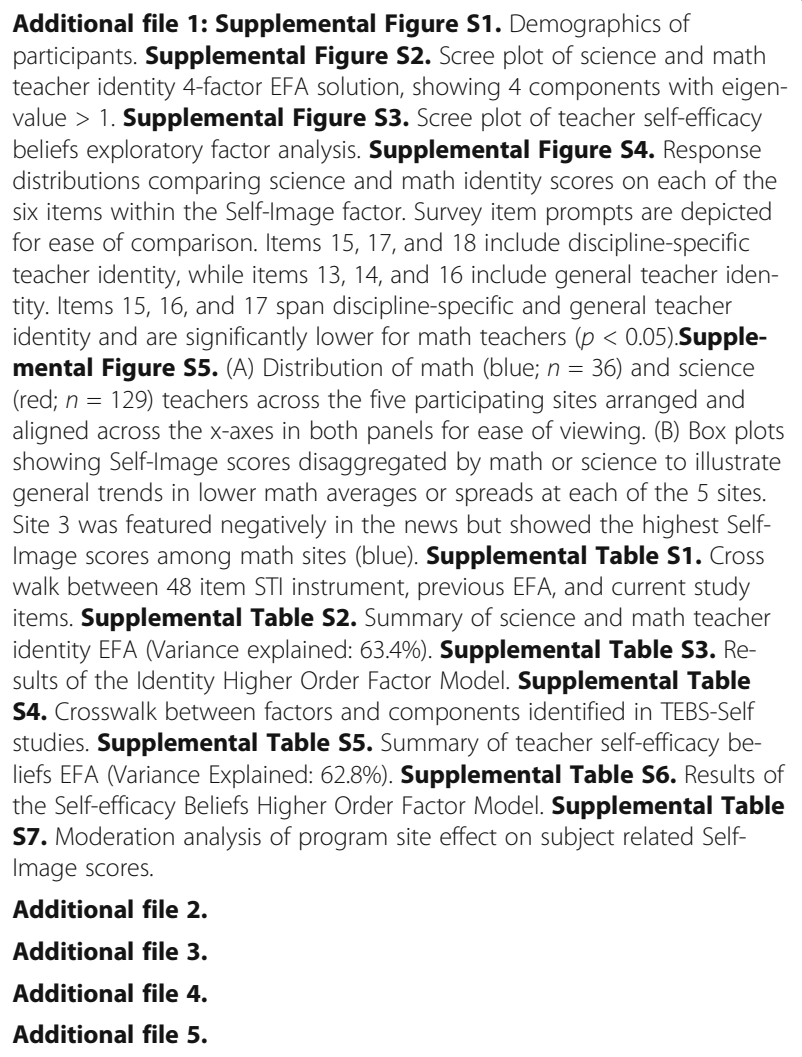

\section{Abbreviations}

STEM: Science, technology, engineering, and mathematics; STI: Science teacher identity; TES: Teacher efficacy scale; TEBS-Self: Teachers' Efficacy Beliefs System-Self; CoP: Communities of practice; SNA: Social network analysis; EFA: Exploratory factor analysis; PCA: Principal component analysis 


\section{Acknowledgements}

The authors would like to gratefully acknowledge the financial support from Middle Tennessee State University and our colleagues for providing valuable feedback on early drafts of this manuscript.

\section{Authors' contributions}

S.J.P, B.O., M.B., G.R., M.M-S, K.S., and G.T.R made substantial contributions to the conception, design, and interpretation of data in this study presented in this manuscript. Y.Z. made substantial contributions to the analysis and interpretation of the data. S.S. \& J.W.R. made substantial contributions to the drafting and editing of the manuscript. The authors read and approved the final manuscript.

\section{Funding}

This work was supported in part by National Science Foundation (NSF) Awards DUE-1917181, DUE-1660665 and DUE-1660736. The findings, conclusions, and opinions herein represent the views of the authors and do not necessarily represent the view of personnel affiliated with NSF.

\section{Availability of data and materials}

Not applicable.

\section{Competing interests}

The authors declare that they have no competing interests.

\section{Author details}

${ }^{1}$ Tennessee STEM Education Center, Middle Tennessee State University, Murfreesboro, TN 37132, USA. ${ }^{2}$ Department of Applied Mathematics and Statistics, Stony Brook University, Stony Brook, NY 11790, USA. ${ }^{3}$ Department of Global Leadership and Management, University of Missouri - St. Louis, St. Louis, MO 63121, USA. ${ }^{4}$ Mathematics and Science Education Doctoral Program, Middle Tennessee State University, Murfreesboro, TN 37132, USA. ${ }^{5}$ Department of Teaching and Learning, University of Wisconsin Oshkosh, Oshkosh, WI 54901, USA. 'Department of Curriculum and Instruction, University of Minnesota, St Paul, MN 55108, USA. ${ }^{7}$ Department of STEM Education, University of Kentucky, Lexington, KY 40506, USA. ${ }^{8}$ Institute for STEM Education, Stony Brook University, Stony Brook, NY 11794, USA.

${ }^{9}$ Chemistry Department, Middle Tennessee State University, Murfreesboro, TN 37132, USA.

\section{Received: 24 April 2020 Accepted: 24 January 2021}

\section{Published online: 14 April 2021}

\section{References}

Aldridge, J. M., \& Fraser, B. J. (2016). Teachers' views of their school climate and its relationship with teacher self-efficacy and job satisfaction. Learning Environments Research, 19, 291-307. https://doi.org/10.1007/s10984-015-9198-x.

Allinder, R. M. (1994). The relationship between efficacy and the instructional practices of special education teachers and consultants. Teacher Education and Special Education, 17, 86-95. https://doi.org/10.1177/ 088840649401700203

Alsup, J. (2006). Teacher identity discourses: Negotiating personal and professional spaces. Mahwah: Lawrence Erlbaum Associates, Inc., Publishers.

Ashcraft, M. H., Krause, J. A., \& Hopko, D. R. (2007). Is math anxiety a mathematical learning disability? In D. B. Berch, \& M. M. M. Mazzocco (Eds.), Why is math so hard for some children? The nature and origins of mathematical learning difficulties and disabilities, (pp. 329-348). Baltimore: Paul H Brookes Publishing.

Bandura, A. (1977). Self-efficacy: Toward a unifying theory of behavioral change. Psychological Review, 84, 191-215. https://doi.org/10.1037/0033-295X.84.2.191.

Beauchamp, C., \& Thomas, L. (2009). Understanding teacher identity: An overview of issues in the literature and implications for teacher education. Cambridge Journal of Education, 39, 175-189. https://doi.org/10.1080/ 03057640902902252.

Beijaard, D., Meijer, P. C., \& Verloop, N. (2004). Reconsidering research on teachers' professional identity. Teaching and Teacher Education, 20, 107-128. https:// doi.org/10.1016/j.tate.2003.07.001.

Berger, J.-L., \& Lê Van, K. (2018). Teacher professional identity as multidimensional: mapping its components and examining their associations with general pedagogical beliefs. Educational Studies, 45, 1-19. https://doi.org/10.1080/ 03055698.2018.1446324
Billingsley, B. S. (2004). Special education teacher retention and attrition: A critical analysis of the research literature. The Journal of Special Education, 38, 39-55. https://doi.org/10.1177/00224669040380010401.

Bobbett, J. J. (2001). School culture, teacher efficacy, and decision making in demonstrably effective and ineffective schools (Unpublished Doctoral Dissertation), Louisiana State University, Baton Rouge.

Buchanan, J. (2012). Telling tales out of school: Exploring why former teachers are not returning to the classroom. Australian Journal of Education, 56, 205-217. https://doi.org/10.1177/000494411205600207.

Burley, W. W., Hall, B. W., Villeme, M. G., \& Brockmeir, L. L. (1991, April). A path analysis of the mediating role of efficacy in first year teachers 'experiences, reactions and plans. Chicago: Paper presented the annual meeting of the American Educational Research Association.

Burt, R. S. (2000). The network structure of social capital. Research in Organizational Behavior, 22, 345-423. https://doi.org/10.1016/S01913085(00)22009-1.

Burt, R. S. (2004). Structural holes and good ideas. American Journal of Sociology, 110(2), 349-399. https://doi.org/10.1086/421787.

Canrinus, E. T., Helms-Lorenz, M., Beijaard, D., Buitink, J., \& Hofman, A. (2011). Profiling teachers' sense of professional identity. Educational Studies, 37(5), 593-608. https://doi.org/10.1080/03055698.2010.539857.

Canrinus, E. T., Helms-Lorenz, M., Beijaard, D., Buitink, J., \& Hofman, A. (2012). Selfefficacy, job satisfaction, motivation and commitment: Exploring the relationships between indicators of teachers' professional identity. European Journal of Psychology of Education, 27, 115-132. https://doi.org/10.1007/ s10212-011-0069-2.

Caprara, G. V., Barbaranelli, C., Steca, P., \& Malone, P. S. (2006). Teachers' selfefficacy beliefs as determinants of job satisfaction and students' academic achievement: a study at the school level. Journal of School Psychology, 44, 473-490. https://doi.org/10.1016/j.jsp.2006.09.001.

Chan, W.-Y., Lau, S., Nie, Y., Lim, S., \& Hogan, D. (2008). Organizational and personal predictors of teacher commitment: The mediating role of teacher efficacy and identification with school. American Educational Research Journal, 45, 597-630. https://doi.org/10.3102/0002831208318259.

Chi, H. J. (2009). Development and examination of a model of Science Teacher Identity (STI). (Unpublished doctoral dissertation), The Ohio State University, Columbus, $\mathrm{OH}$.

Costello, A. B., \& Osborne, J. W. (2005). Best practices in exploratory factor analysis: Four recommendations for getting the most from your analysis. Practical Assessment, Research \& Evaluation, 10(7), 1-9. https://doi.org/10.7275/ jyj1-4868.

Cross, R., Laseter, T., Parker, A., \& Velasquez, G. (2006). Using social network analysis to improve communities of practice. California Management Review, 49, 32-60. https://doi.org/10.2307/41166370.

Danielewicz, J. (2001). Teaching selves: Identity, pedagogy, and teacher education. Albany: State University of New York Press.

Darling-Hammond, L. (2017). Teacher education around the world: What can we learn from international practice? European Journal of Teacher Education, 40, 291-309. https://doi.org/10.1080/02619768.2017.1315399.

Darling-Hammond, L., Burns, D., Campbell, C., Goodwin, A. L., Hammerness, K., Low, E.-L., ... Zeichner, K. (2017). Empowered educators: How high-performing systems shape teaching quality around the world. San Francisco: Jossey-Bass Publisher.

Dellinger, A. B. (2001). A study of the measurement and sources of teachers' self and collective efficacy beliefs in professional learning environments. (Unpublished Doctoral Dissertation), Louisiana State University, Baton Rouge.

Dellinger, A. B., Bobbett, J. J., Olivier, D. F., \& Ellett, C. D. (2008). Measuring teachers' self-efficacy beliefs: Development and use of the TEBS-Self. Teaching and Teacher Education, 24, 751-766. https://doi.org/10.1016/j.tate.2007.02.010.

Eick, C. J., \& Reed, C. J. (2002). What makes an inquiry-oriented science teacher? The influence of learning histories on student teacher role identity and practice. Science Education, 86, 401-416. https://doi.org/10.1002/sce.10020.

Friedman, I. A., \& Kass, E. (2002). Teacher self-efficacy: a classroom-organization conceptualization. Teaching and Teacher Education, 18, 675-686. https://doi. org/10.1016/S0742-051X(02)00027-6.

Friedrichsen, P., Lannin, J., Abell, S., Arbaugh, F., \& Volkmann, M. (2008). Examining incoming identities in an alternative certification program in mathematics and science. Eurasia Journal of Mathematics, Science and Technology Education, 4, 169-182. https://doi.org/10.12973/ejmste/75316.

Gates, B. (2020). Responding to COVID-19-a once-in-a-century pandemic? New England Journal of Medicine, 382, 1677-1679. https://doi.org/10.1056/ NEJMp2003762. 
Gee, J. P. (2000). Identity as an analytic lens for research in education. Review of Research in Education, 25, 99-125. https://doi.org/10.3102/ 0091732 X025001099.

Gibson, S., \& Dembo, M. H. (1984). Teacher efficacy: a construct validation. Journal of Educational Psychology, 76, 569-582. https://doi.org/10.1037/0022-0663.76. 4.569 .

Glickman, C., \& Tamashiro, R. (1982). A comparison of first-year, fifth-year, and former teachers on efficacy, ego development, and problem solving. Psychology in the Schools, 19, 558-562. https://doi.org/10.1002/15206807(198210)19:4<558::AID-PITS2310190426>3.0.CO;2-F.

Goos, M. E., \& Bennison, A. (2008). Developing a communal identity as beginning teachers of mathematics: Emergence of an online community of practice. Journal of Mathematics Teacher Education, 11, 41-60. https://doi.org/10.1007/ s10857-007-9061-9.

Hair, J. F., Black, W. C., Babin, B. J., \& Anderson, R. E. (2009). Multivariate data analysis with readings, (7th ed., ). Englewood Cliffs: Prentice-Hall William.

Hausman, C. S., \& Goldring, E. B. (2001). Sustaining teacher commitment: The role of professional communities. Peabody Journal of Education, 76, 30-51. https://doi.org/10.1207/S15327930pje7602_3.

Helms, J. V. (1998). Science — and me: Subject matter and identity in secondary school science teachers. Journal of Research in Science Teaching, 35, 811-834. https://doi.org/10.1002/(SICl) 1098-2736(199809)35:7<811::AID-TEA9>3.0.CO;2-O

Hong, J. Y. (2010). Pre-service and beginning teachers' professional identity and its relation to dropping out of the profession. Teaching and Teacher Education, 26, 1530-1543. https://doi.org/10.1016/j.tate.2010.06.003.

Ingersoll, R. (2012). Beginning teacher induction: what the data tell us. Phi Delta Kappan, 93(8), 47-51. https://doi.org/10.1177/003172171209300811.

Ingersoll, R., \& Smith, T. (2003). The wrong solution to the teacher shortage. Educational Leadership, 60(8), 30 Retrieved from https://www.gse.upenn.edu/ pdf/rmi/EL_TheWrongSolution_to_theTeacherShortage.pdf.

Ingersoll, R. M. (2001). Teacher turnover and teacher shortages: An organizational analysis. American Educational Research Journal, 38, 499-534. https://doi.org/ 10.3102/00028312038003499.

Ingersoll, R. M., \& Strong, M. (2011). The impact of induction and mentoring programs for beginning teachers: a critical review of the research. Review of Educational Research, 81, 201-233. https://doi.org/10.3102/0034654311403323.

Kelley, T. R., Knowles, J. G., Holland, J. D., \& Han, J. (2020). Increasing high school teachers self-efficacy for integrated STEM instruction through a collaborative community of practice. International Journal of STEM Education, 7, 1-13. https://doi.org/10.1186/s40594-020-00211-w.

Klassen, R. M., \& Chiu, M. M. (2010). Effects on teachers' self-efficacy and job satisfaction: Teacher gender, years of experience, and job stress. Journal of Educational Psychology, 102, 741. https://doi.org/10.1037/a0019237.

Korthagen, F. A. J. (2010). Situated learning theory and the pedagogy of teacher education: Towards an integrative view of teacher behavior and teacher learning. Teaching and Teacher Education, 26, 98-106. https://doi.org/10.1016/ j.tate.2009.05.001.

Lave, J., \& Wenger, E. (1991). Situated learning: legitimate peripheral participation. Cambridge: Cambridge University Press.

Luehmann, A. L. (2007). Identity development as a lens to science teacher preparation. Science Education, 91, 822-839. https://doi.org/10.1002/sce.20209.

Luehmann, A. L. (2008). Using blogging in support of teacher professional identity development: a case study. Journal of the Learning Sciences, 17, 287337. https://doi.org/10.1080/10508400802192706.

Luehmann, A. L., \& Tinelli, L. (2008). Teacher professional identity development with social networking technologies: Learning through blogging. Educational Media International, 45, 323-333. https://doi.org/10.1080/09523980802573263.

Mack, J. C., Johnson, A., Jones-Rincon, A., Tsatenawa, V., \& Howard, K. (2019). Why do teachers leave? A comprehensive occupational health study evaluating intent-to-quit in public school teachers. Journal of Applied Biobehavioral Research, 24, e12160. https://doi.org/10.1111/jabr.12160.

Marsden, P. V. (1987). Core discussion networks of Americans. American Sociological Review, 52, 122-131. https://doi.org/10.2307/2095397.

McIntyre, J., \& Hobson, A. J. (2015). Supporting beginner teacher identity development: External mentors and the third space. Research Papers in Education, 31, 133-158. https://doi.org/10.1080/02671522.2015.1015438.

Mehra, A., Borgatti, S. P., Soltis, S., Floyd, T., Halgin, D. S., Ofem, B., \& Lopez-Kidwell, V. (2014). Imaginary worlds: using visual network scales to capture perceptions of social networks. In D. J. Brass, G. Labianca, A. Mehra, D. S. Halgin, \& S. P. Borgatti (Eds.), Contemporary perspectives on organizational social networks, (pp. 315-336). Bingley: Emerald Group Publishing Limited.
Mitchell, T. R., Holtom, B. C., Lee, T. W., Sablynski, C. J., \& Erez, M. (2001). Why people stay: Using job embeddedness to predict voluntary turnover. Academy of Management Journal, 44, 1102-1121. https://doi.org/10.5465/ 3069391.

Moore, M., \& Hofman, J. E. (1988). Professional identity in institutions of higher learning in Israel. Higher Education, 17, 69-79. https://doi.org/10.1007/ bf00130900.

National Research Council (2010). Preparing teachers: Building evidence for sound policy. Washington, D.C.: National Academies Press.

Ofem, B., Polizzi, S. J., Rushton, G. T., Beeth, M., Couch, B., Doering, J., .. Sheppard, K. (2021). Looking at out STEM teacher workforce: How to model self-efficacy. Economic Development Quarterly, 35(1), 40-52. https://doi.org/10. $1177 / 0891242420973758$.

Olivier, D. F. (2000). Teacher personal and school culture characteristics in effective schools: Toward a model of a professional learning community. (Unpublished Doctoral Dissertation), Louisiana State University, Baton Rouge, LA.

Polizzi, S. J., Jaggernauth, J., Ray, H. E., Callahan, B., \& Rushton, G. T. (2015). Highly qualified or highly unqualified? A longitudinal study of America's Public High School Biology Teachers. BioScience, 65, 812-821. https://doi.org/10.1093/ biosci/biv093.

Polizzi, S. J., Ofem, B., Coyle, W., Lundquist, K., \& Rushton, G. T. (2019a). The use of visual network scales in teacher leader development. Teaching and Teacher Education, 83, 42-53. https://doi.org/10.1016/j.tate.2019.03.018.

Polizzi, S. J., Ofem, B., Coyle, W., Lundquist, K., \& Rushton, G. T. (2019b). Social network data from teacher leader development. Data in Brief, 83, 42-53. https://doi.org/10.1016/j.dib.2019.104182.

R Core Team (Producer) (2019). R: A language and environment for statistical computing. Vienna: R Foundation for Statistical Computing URL https://www. R-project.org/.

Reckhow, S., \& Snyder, J. W. (2014). The expanding role of philanthropy in education politics. Educational Researcher, 43, 186-195. https://doi.org/10. 3102/0013189x14536607.

Reeves, T. D., \& Marbach-Ad, G. (2016). Contemporary test validity in theory and practice: A primer for discipline-based education researchers. CBE Life Sciences Education, 15, rm1. https://doi.org/10.1187/cbe.15-08-0183.

Richardson, S. (2018). Towards a 2026 STEM education: Implications of convergent science for K-12 STEM teacher preparation in the face of changing demographics. Washington, DC: Presentation given at the 2018 Noyce Summit.

Riggs, I., Diaz, E., Riggs, M., Jesunathadas, J., Brasch, K., Torner, J., ... Pelletier, A. (1994). Impacting elementary science teachers' beliefs and performance through teacher enhancement for science instruction in diverse settings. Anaheim: Paper presented at the National Association for Research in Science Teaching.

Rots, I., Aelterman, A., Vlerick, P., \& Vermeulen, K. (2007). Teacher education, graduates' teaching commitment and entrance into the teaching profession. Teaching and Teacher Education, 23, 543-556. https://doi.org/10.1016/j.tate. 2007.01.012.

Rotter, J. B. (1966). Generalized expectancies for internal versus external control of reinforcement. Psychological Monographs: General and Applied, 80, 1-28. https://doi.org/10.1037/h0092976.

Saka, Y., Southerland, S. A., Kittleson, J., \& Hutner, T. (2013). Understanding the induction of a science teacher: The interaction of identity and context. Research in Science Education, 43, 1221-1244. https://doi.org/10.1007/s11165-012-9310-5.

Sammons, P., Day, C., Kington, A., Gu, Q., Stobart, G., \& Smees, R. (2007). Exploring variations in teachers' work, lives and their effects on pupils: key findings and implications from a longitudinal mixed-method study. British Educational Research Journal, 33, 681-701. https://doi.org/10.1080/01411920701582264.

Santos, J. R. A. (1999). Cronbach's alpha: a tool for assessing the reliability of scales. Journal of Extension, 37(2), 1-5 Retrieved from https://www.joe.org/ joe/1999april/tt3.php.

Schenkel, A., Teigland, R., \& Borgatti, S. P. (2001). Theorizing structural properties of communities of practice: a social network approach. Poster presented at the Academy of Management annual conference. Retrieved from https://www. researchgate.net/publication/274072791_Theorizing_structural_properties_ of_communities_of_practice_A_social_network_approach.

Schepens, A., Aelterman, A., \& Vlerick, P. (2009). Student teachers' professional identity formation: between being born as a teacher and becoming one. Educational Studies, 35, 361-378. https://doi.org/10.1080/03055690802648317.

Settlage, J., Southerland, S. A., Smith, L. K., \& Ceglie, R. (2009). Constructing a doubt-free teaching self: self-efficacy, teacher identity, and science instruction within diverse settings. Journal of Research in Science Teaching, 46, 102-125. https://doi.org/10.1002/tea.20268. 
Sfard, A. (1998). On two metaphors for learning and the dangers of choosing just one. Educational Researcher, 27(2), 4-13. https://doi.org/10.3102/ $0013189 \times 027002004$.

Simpson, A., \& Bouhafa, Y. (2020). Youths' and adults' identity in STEM: a systematic literature review. Journal for STEM Education Research, 3, 167-194. https://doi.org/10.1007/s41979-020-00034-y.

Skaalvik, E. M., \& Skaalvik, S. (2011). Teacher job satisfaction and motivation to leave the teaching profession: relations with school context, feeling of belonging, and emotional exhaustion. Teaching and Teacher Education, 27, 1029-1038. https://doi.org/10.1016/j.tate.2011.04.001.

Soltis, S. M., Agneessens, F., Sasovova, Z., \& Labianca, G. (2013). A social network perspective on turnover intentions: The role of distributive justice and social support. Human Resource Management, 52, 561-584. https://doi.org/10.1002/ hrm.21542.

Starr, S., Haley, H.-L., Mazor, K. M., Ferguson, W., Philbin, M., \& Quirk, M. (2006). Initial testing of an instrument to measure teacher identity in physicians. Teaching and Learning in Medicine, 18, 117-125. https://doi.org/10.1207/ s15328015t Im1802_5.

Sutherland, L., Howard, S., \& Markauskaite, L. (2010). Professional identity creation: Examining the development of beginning preservice teachers' understanding of their work as teachers. Teaching and Teacher Education, 26, 455-465. https://doi.org/10.1016/j.tate.2009.06.006.

Sweitzer, V. (2009). Towards a theory of doctoral student professional identity development: a developmental networks approach. The Journal of Higher Education, 80, 1-33. https://doi.org/10.1080/00221546.2009.11772128.

Tschannen-Moran, M., \& Hoy, A. W. (2001). Teacher efficacy: capturing an elusive construct. Teaching and Teacher Education, 17, 783-805. https://doi.org/10. 1016/S0742-051X(01)00036-1.

Tschannen-Moran, M., Hoy, A. W., \& Hoy, W. K. (1998). Teacher efficacy: its meaning and measure. Review of Educational Research, 68, 202-248. https:// doi.org/10.3102/00346543068002202

Varelas, M., House, R., \& Wenzel, S. (2005). Beginning teachers immersed into science: scientist and science teacher identities. Science Education, 89, 492 516. https://doi.org/10.1002/sce.20047.

Vygotsky, L. S. (1980). Mind in society: The development of higher psychological processes. Cambridge: Harvard University Press.

Ware, H., \& Kitsantas, A. (2007). Teacher and collective efficacy beliefs as predictors of professional commitment. The Journal of Educational Research, 100, 303-310. https://doi.org/10.3200/JOER.100.5.303-310.

Wenger, E. (1998). Communities of practice: learning as a social system. Systems Thinker, 9, 2-3.

Wenger-Trayner, E., \& Wenger-Trayner, B. (2015). Learning in landscapes of practice: a framework. In E. Wenger-Trayner, M. Fenton-O'Creevy, S. Hutchinson, C. Kubiak, \& B. Wenger-Trayner (Eds.), Learning in landscapes of practice: boundaries, identity, and knowledgeability in practice-based learning, (pp. 13-29). New York: Routledge.

Yost, D. S. (2006). Reflection and self-efficacy: enhancing the retention of qualified teachers from a teacher education perspective. Teacher Education Quarterly, 33, 59-76 Retrieved from https://www.jstor.org/stable/23478871.

\section{Publisher's Note}

Springer Nature remains neutral with regard to jurisdictional claims in published maps and institutional affiliations.

\section{Submit your manuscript to a SpringerOpen ${ }^{\circ}$ journal and benefit from:}

- Convenient online submission

- Rigorous peer review

- Open access: articles freely available online

- High visibility within the field

- Retaining the copyright to your article

Submit your next manuscript at $\boldsymbol{\nabla}$ springeropen.com 